\title{
DESIGN AND MODELING STUDIES OF TUBE END EXPANSION USING
}

\section{RESPONSE SURFACE METHODOLOGY}

\section{VENUGOPAL}

Associate Professor, Department of Mechanical Engineering, MLR Institute of Technology, Hyderabad, Telangana, India

\begin{abstract}
The production of various profiles on the ends of the tubes is referred as tube end forming process. In the present work, the elevated temperature forming studies have been performed. The thin walled tubes have been subjected to expansion process, and the process parameters namely the die angle, the die ratio and the operating temperatures that influence the expansion of tube ends at elevated temperatures is carried out. The range of operating parameters has been identified by performing simulation studies. The expansion parameters have been evaluated for AA2014 alloy for performing the simulation studies. Experimental matrix has been developed from the feasible range, got from the simulation results. Design of experiments is used for the optimization of process parameters. Response Surface Method's (RSM) and Box-Behenken design (BBD) is used for developing the mathematical model for expansion. Analysis of variance (ANOVA) is used to analyze the influence of process parameters on the expansion of tube ends. The effect of various process combinations of expansion are analyzed through graphical representations. The developed model is found to be appropriate, as the coefficient of determination value is very high and is equal to 0.9726 . The predicted values are found to coincide well with the experimental results, within acceptable error limits.

KEYWORDS: Expansion; Optimization; RSM; ANOVA; BBD \& Tube
\end{abstract}

Received: Nov 17, 2017; Accepted: Dec 08, 2017; Published: Jan 05, 2018; Paper Id.: IJMPERDFEB201820

\section{INTRODUCTION}

The production of various complex shaped profiles on the ends of the tubes is referred to as the end forming process. It finds application in many fields, such as in power transmission applications, as fuel lines and exhaust pipes, as hydraulic cylinders and heat exchangers etc. In metal forming processes, it is essential that the metal deforms plastically without any fracture. Tube end forming process is governed by various process parameters namely punch/die cone angle, the ratio between punch radius and the initial reference radius, friction, operating temperature, tube thickness etc.

Very little literature is available on end-forming of tubes. Rosa et al [1-2] conducted the experimental and theoretical investigations on the external and internal inversions of thin-walled tubes. They understood the modes of deformation during the free curved internal and external inversion of tubes. Almeida et al [3] produced tubular parts by expansion and reduction process on thin walled tubes using a die. The authors established the formability principles by both experimental and simulation. The authors used I-FORM2 to simulate the process and validated the methodology with experimental results. Alves et al [4] performed tube end forming studies on AA6060 alloys. The tubes failed predominantly by ductile fracture, wrinkling and local buckling. The cold state expansion and reduction of thin-walled PVC tubes using a die was studied by Alves et al [5]. The authors performed the study on PVC tubes. Wang et al [6] have used a controller forming process for enlarging the tube ends. Many authors have 
been using response surface method (RSM) in different applications to optimize the process parameters.

Qi Zhang et al [7] have investigated the rotary swaging process of tubes by finite-element simulations using Forge 2011 3D instance. They observed that the necking of the tube ends before tube hydro forming process and internal gear machining process. Barati [8] has determined the flow stress and the friction factor for AZ61 alloy. By conducting the ring compression test he evaluated both the interfacial friction and the flow curve of a material. Henriksen et al [9] have presented a new method of connecting pipe to flange without welding. This method is a cold forming process that is based on plastic expansion/deformation of the pipe into a modified standard flange by use of a cold forming tool. A non-linear FE model of the flange, pipe and forming tool is developed and analyzed using Abacus. It is showed that the simulation results achieve a good accordance with experimental results.

Sieczkarek et al [10] have investigated an incremental gear forming process with a simple one-wedge forming tool, to offer conditions with a high tool load. For the extension of the tool's life- time, different surface concepts and combinations with CrAlN PVD-coatings were investigated. Centeno et al [11] gave an experimental procedure to determine the fracture strains and the critical values of ductile damage at the onset of failure by fracture in tube forming. The authors investigated the crack opening in mode I (by tension) and combines experimentation in tube expansion with analytical modelling using membrane analysis, circle grid analysis and finite element modelling. Borrego et al [12] have investigated the ability of the single-point incremental forming process to perform hole-flanges in a single stage, contributing to a better understanding of the formability of the sheet. The authors conducted the experiments on 7075-O aluminium alloy sheets.

Though many authors have utilized the optimization techniques such as Taguchi method, Response Surface Methodology etc, no literature is available on its applicability on tube end forming process. Moreover, the hot forming material parameters of AA2014 has never been discussed in any research articles and its applicability in the FEA based simulation studies using simulation packages like DEFORM 2D. In the present study, the expansion values obtained by varying forming parameters such as die ratio $\left(\mathrm{r}_{\mathrm{p}} / \mathrm{r}_{\mathrm{o}}\right)$, die angle $(\alpha)$ and operating temperature $(T)$ are optimized by applying the response surface method (RSM).

\section{EXPERIMENTAL WORK}

\section{Materials}

The tube work piece used in the present investigation is made of AA2014 alloy. The major alloying elements of the alloy are $\mathrm{Al}-4.08 \mathrm{Cu}-0.422 \mathrm{Mg}-0.697 \mathrm{Si}-0.605 \mathrm{Mn}$. Disc compression tests were performed on the samples to find the material constants at cold and hot conditions using hydraulic press of 50 ton capacity. The following are the flow-stress equations for the material at cold and hot working conditions respectively, which has been used in the finite element based simulation trials performed for the tube expansion problem.

$$
\begin{aligned}
& \sigma=699 \varepsilon^{0.12} \mathrm{MPa} \\
& \dot{\mathcal{E}}=2.42 \times 10^{8}[\sinh (0.00267 \sigma)]^{5.978} \exp \left(-\frac{145440}{R T}\right)
\end{aligned}
$$

\section{EXPERIMENTAL PROCEDURE}

A previous study [13] performed by the authors revealed that the alloy cannot be processed in the cold state. So, 
in the present investigation, the tube expansion study was performed at elevated temperatures and the process has been modeled using the statistical modeling technique. Response Surface Methodology (RSM) and Finite Element Analysis based simulations have been performed to arrive at the feasible range of the experimental matrix for RSM. Simulations were performed on thin walled tubes of $2 \mathrm{~mm}$ thickness and $90 \mathrm{~mm}$ length. Forming dies of different expansion ratios $\left(\mathrm{r}_{\mathrm{p}} / \mathrm{r}_{\mathrm{o}}\right)$ namely $1.39,1.53$ and 1.67 and different cone angles $(\alpha)$ namely $15^{\circ}, 30^{\circ}$ and $45^{\circ}$ were used to expand the tube ends, where $r_{p} / r_{0}$, the expansion ratio is the ratio between ' $r_{p}$ ' the punch radius at its top and ' $r_{0}$ ' the punch radius at its bottom and ' $\alpha$ ' is the forming angle or the die cone angle. The tubes were expanded at different temperatures namely $300^{\circ} \mathrm{C}, 400^{\circ} \mathrm{C}$ and $500^{\circ} \mathrm{C}$. During the tests, the temperature of the specimen was kept at constant until the tube was stretched to failure. As the hot deformation study involves heating the samples for very long time, it was planned to perform simulation studies to arrive at the possible range of temperatures at which, the experiments could be conducted as per the design matrix dictated by the RSM method. Different disc compression tests at different temperatures and strain rates were performed to arrive at the material parameters that constitute the flow behavior.

Cylindrical samples with size of $16 \mathrm{~mm}$ diameter and $16 \mathrm{~mm}$ height were machined from commercial available ingots of AA2014 alloy. The compression tests were carried out on a hydraulic press of 50 ton capacity machine at strain rates of $0.03-0.1 \mathrm{~s}^{-1}$ and deformation temperatures of $300-550{ }^{\circ} \mathrm{C}$. The samples were deformed to $60 \%$ of their original height. The load versus displacement data gathered from the compression tests were used to plot the true stress versus true strain curves. The data obtained from the stress-strain curves of hot compression tests were then used to determine the activation energy for the hot deformation of 2014 alloy.

\section{RESPONSE SURFACE METHODOLOGY (RSM)}

RSM is a mathematical and statistical tool, used to design and model experiments, to gain meaningful knowledge by performing less number of experiments. The relationship between the output variable and the input variable can be related by performing experiments, as per carefully designed experimental combinations. A series of tests, called runs, will be performed in which the changes in the output will be analyzed with respect to the changes in the input variables. The response will be viewed in 3D surfaces called response curves, which enables viewing the output pictorially for the corresponding changes in two of its input variables.

\section{Box-Behnken Design (Bbd)}

Box-Behnken design is one of the best methods among the different RSM techniques. This method needs a minimum of three equally spaced levels. The data used in the model should be sufficient to generate a quadratic model, and the ratio of the experimental points to the number of coefficients in the quadratic model should be between 1.5 and 2.6. The analysis will be done by performing the experiments by varying the parameters factorial in blocks or groups. The high and low values of the factors will be considered in the blocks.

\section{Response Equation for Linear Expansion}

In the present work, Box-Behnken design has been utilized to develop the model for tube expansion. The feasible range of the deformation temperatures were arrived at from the hot forming simulation studies. The simulations were performed on DEFORM 2D, a FEA based simulation software. The flow curve was incorporated into the package, by incorporating the material constants obtained from the hot compression tests. Simulations were then performed on the model, developed to arrive at the feasible range of process parameters. The experimental matrix so developed is shown in 
Table 1. The linear expansion, which is the distance by which the tube has been expanded from the time the die, starts penetrating inside the tube to the limit, where the tube starts cracking has been measured experimentally and is given in Table 1.

Table 1: Experimental Layout for the Box-Behenken Design

\begin{tabular}{|c|c|c|c|c|}
\hline \multirow[b]{2}{*}{ Run Order } & \multicolumn{3}{|c|}{ Factors } & \multirow[b]{2}{*}{$\begin{array}{l}\text { Linear } \\
\text { Expansion } \\
(\mathbf{m m})\end{array}$} \\
\hline & $\begin{array}{c}\text { Die Ratio } \\
\left(\mathbf{r}_{\mathrm{p}} / \mathbf{r}_{0}\right)\end{array}$ & $\begin{array}{c}\text { Die Angle } \\
(\alpha) \text { in } \\
\text { Degrees }\end{array}$ & $\begin{array}{c}\text { Operating } \\
\text { Temperature } \\
\text { (t) In }{ }^{0} \mathrm{c}\end{array}$ & \\
\hline 1 & 1.39 & 30 & 500 & 9.0 \\
\hline 2 & 1.53 & 30 & 400 & 16.5 \\
\hline 3 & 1.53 & 15 & 300 & 10.0 \\
\hline 4 & 1.53 & 45 & 300 & 3.0 \\
\hline 5 & 1.67 & 15 & 400 & 24.0 \\
\hline 6 & 1.39 & 15 & 400 & 16.0 \\
\hline 7 & 1.67 & 30 & 300 & 4.2 \\
\hline 8 & 1.53 & 45 & 500 & 8.0 \\
\hline 9 & 1.53 & 30 & 400 & 16.5 \\
\hline 10 & 1.39 & 45 & 400 & 8.5 \\
\hline 11 & 1.53 & 30 & 400 & 16.5 \\
\hline 12 & 1.39 & 30 & 300 & 5.0 \\
\hline 13 & 1.53 & 30 & 400 & 16.5 \\
\hline 14 & 1.53 & 15 & 500 & 18.4 \\
\hline 15 & 1.67 & 30 & 500 & 10.0 \\
\hline 16 & 1.67 & 45 & 400 & 10.2 \\
\hline 17 & 1.53 & 30 & 400 & 16.5 \\
\hline
\end{tabular}

The response equation for the linear expansion of tube ends in terms of the actual factors obtained from the RSM model is given by

Linear Expansion $=-408.94305+379.51531 *$ Ratio+0.92167*Angle+ $\quad 0.56782 *$ Temperature $0.75000 *$ Ratio*Angle $+0.032143 *$ Ratio*Temperature -5.66667 E-004*Angle*Temperature $-117.98469 *$ Ratio $^{2}+$ $2.16667 \mathrm{E}-003 *$ Angle $^{2}-7.13750 \mathrm{E}-004 *$ Temperature $^{2}$

\section{RESULTS AND DISCUSSIONS}

The analysis of variance (ANOVA) is used to determine the most significant factor among all the process parameters, which are affecting the output quality characteristics using the quantities such as degrees of freedom, sum of squares and P-value. Table 2 gives the model summary statistics. It reveals that quadratic model is suggested model than the linear and the 2FI models. So, the quadratic model has been used for further analysis. Table 3 gives the ANOVA for the response surface model for the expansion of tube ends. The Model F-value of 27.61 implies that the model is significant. There is only a $0.01 \%$ chance that a "Model F-Value" this large could occur due to noise. Values of "Prob> F" less than 0.05 indicate model terms are significant. In this case $\mathrm{A}, \mathrm{B}, \mathrm{C}, \mathrm{A}^{2}$ and $\mathrm{C}^{2}$ are significant model terms.

Table 2: Model Summary Statistics

\begin{tabular}{|l|c|c|c|c|}
\hline \multicolumn{1}{|c|}{ Source } & Std. Dev. & R-Squared & Press & Remarks \\
\hline Linear & 4.59 & 0.4938 & 486.61 & - \\
\hline 2FI & 5.10 & 0.5190 & 978.34 & - \\
\hline Quadratic & 1.45 & 0.9726 & 236.84 & Suggested \\
\hline
\end{tabular}


Table 3: ANOVA Table for Response Surface Model for Expansion of Tube Ends

\begin{tabular}{|l|c|c|c|c|c|c|}
\hline \multicolumn{1}{|c|}{ Source } & $\begin{array}{c}\text { Sum of } \\
\text { Squares }\end{array}$ & D. O. F. & $\begin{array}{c}\text { Mean } \\
\text { Squares }\end{array}$ & F-Value & P-Value & Remarks \\
\hline Model & 525.38 & 9 & 58.38 & 27.61 & 0.0001 & Significant \\
\hline A-Ratio & 12.25 & 1 & 12.25 & 5.79 & 0.0470 & Significant \\
\hline B-Angle & 187.21 & 1 & 187.21 & 88.53 & $<0.0001$ & Significant \\
\hline C-Temperature & 67.28 & 1 & 67.28 & 31.82 & 0.0008 & Significant \\
\hline $\mathrm{AB}$ & 9.92 & 1 & 9.92 & 4.69 & 0.0670 & - \\
\hline $\mathrm{AC}$ & 0.81 & 1 & 0.81 & 0.38 & 0.5556 & - \\
\hline $\mathrm{BC}$ & 2.89 & 1 & 2.89 & 1.37 & 0.2807 & - \\
\hline $\mathrm{A}^{2}$ & 22.52 & 1 & 22.52 & 10.65 & 0.0138 & Significant \\
\hline $\mathrm{B}^{2}$ & 1.00 & 1 & 1.00 & 0.47 & 0.5137 & - \\
\hline $\mathrm{C}^{2}$ & 214.50 & 1 & 214.50 & 101.44 & $<0.0001$ & Significant \\
\hline Residual & 14.80 & 7 & 2.11 & - & - & - \\
\hline
\end{tabular}

Table 4: Regression statistics

\begin{tabular}{|l|c|l|c|}
\hline Std. Dev. & 1.45 & R-Squared & 0.9726 \\
\hline Mean & 12.28 & Press & 236.8400 \\
\hline C. V.\% & 11.84 & Adeq. Precision & 17.3610 \\
\hline
\end{tabular}

Table 4 gives the regression statistics of the statistical model. The R- squared value should be close to 1 and in the present case it is 0.9726 which is close to 1 . Therefore, the model is appropriate. "Adeq Precision" gives the ratio of the signal to the noise. A ratio greater than 4 is required for the model to be appropriate. In the present analysis, the ratio is 17.361. So, the model is appropriate and can be used to retrieve the data in the design space. The normal probability plot of the residuals is shown in Figure 2. Residuals are the difference between the observed and the predicted responses. The residuals are useful to check whether the model is adequate or not. The residuals will fall on a straight line, if the difference between the experimental and the predicted values is too close. In the present case, as the residuals are on a straight line, it is concluded that the model has predicted with very little error and can be used to predict the response.

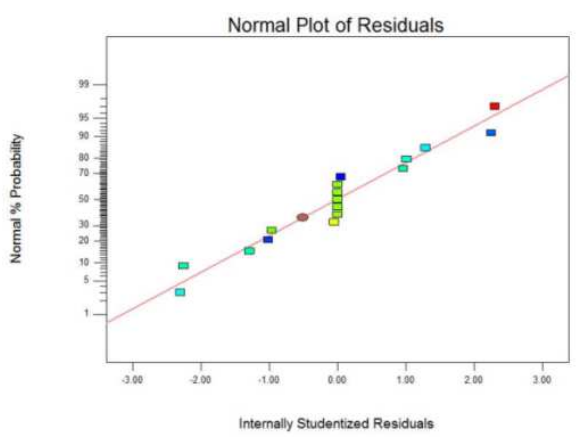

Figure 2: Normal Probability Plot of Residuals for Expansion

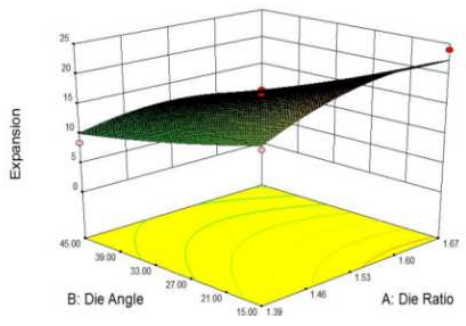

(a) 


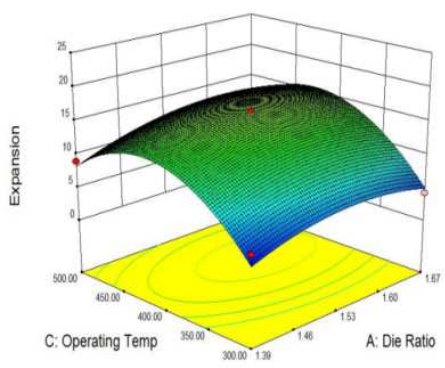

(b)

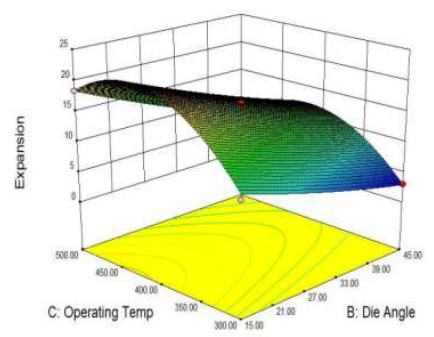

(c)

Figure 3: 3D Surface Graph for the Expansion (A) at Operating Temperature $=4^{\circ} 0^{\circ} \mathrm{c}$, as Die Angle and Die Ratio Varies (B) at Die Angle $=30^{\circ}$, as Operating Temperature and Die Ratio Varies. (C) at Die Ratio = 1.53, As Operating Temperature and Die Angle Varies

Figures 3a, 3b and 3c give the 3D surface graphs of the linear expansion of tube ends. As the model is valid, these 3D surface plots can be used for estimating the linear expansion of tube end values for any suitable combination of the input parameters, namely the die ratio, the die angle and the operating temperature. Figure 3a gives the 3D surface graph for the linear expansion at an operating temperature of $400^{\circ} \mathrm{C}$. The die angle and the die ratio vary. It is found that the linear expansion of the tube increases with increase in the die ratio, and it decreases with increase in the die cone angle.

Figure $3 \mathrm{~b}$ gives the $3 \mathrm{D}$ surface graph for the tube expansion at a die angle of $30^{\circ}$. The operating temperature and the die ratio vary. The expandability of the tube end increases with increase in temperature, and it reached a maximum at a temperature of $450^{\circ} \mathrm{C}$. The tube then buckled with further increase. The same is seen in the graph with a drop in the expansion value beyond $450^{\circ} \mathrm{C}$. The linear expansion is found to be small for the die ratios of 1.67 and 1.39 , and it is more for a die ratio of 1.53. The failure of the tubes starts in the axial direction and it progresses along with the die penetration. Figure $3 \mathrm{c}$ gives the 3D surface graph for the linear expansion for a die ratio of 1.53. It shows that the linear expansion decreases with increasing die angle, and increases with increasing operating temperature but, it starts decreasing after $450^{\circ} \mathrm{C}$. Figure 4 shows the expanded tube for the condition of die ratio1.67, die angle $15^{\circ}$ and operating temperature $400^{\circ} \mathrm{C}$.

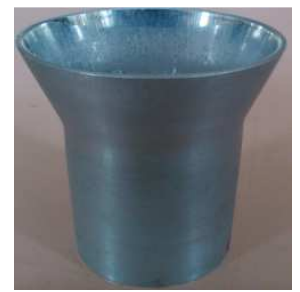

Figure 4: Tube Expanded For the Condition of Die Ratio1.67, Die Angle $15^{\circ}$ and Operating Temperature $400^{\circ} \mathrm{c}$ 


\section{CONCLUSIONS}

In the present study, the process parameters of tube end forming process are optimized by using design of experiment tool. The analysis of tube expansion is carried through the response surface method (RSM). A Box- Behnken design was used to carry out the experimental study. Analysis of variance (ANOVA) was used to analyze the effect of the process parameters on the response. The feasible range of the process parameters were identified by performing FEA studies using DEFORM 2D package. The Arrhenius relation was used as the constitutive relation for the hot forming behavior of the alloy. The material constants such as $\alpha, \mathrm{n}, \mathrm{Q}$ and $\mathrm{A}$ in the Arrhenius relation were determined using compression tests and by drawing stress- stain curves. The die angle is found to be the most important parameter affecting tube expansion, followed by the operating temperature while the die ratio has the least effect. A prediction model has been developed and the expansion values predicted from the model is found to be closer to the experimental values. The 3D surface graphs drawn can be used as a process curve to predict the expansion values for any two combinations of input process parameters within the level chosen for the input parameters. The predicted values of expansion of tube ends matches the experimental values with high value of coefficient of determination $\left(R^{2}=0.9726\right)$.

\section{REFERENCES}

1. Rosa PAR, Rodrgues JMC, Martins PAF (2003), External inversion of thin-walled tubes using a die: experimental and theoretical investigation. International Journal of Machine Tools and Manufacture, 43,787-796.

2. Rosa PAR, Rodrgues JMC, Martins PAF (2004) Internal inversion of thin-walled tubes using a die: experimental and theoretical investigation. International Journal of Machine Tools and Manufacture, 44, 775-784.

3. Almeida BPP, Alves ML, Rosa PAR, Brito AG, Martins PAF (2006), Expansion and reduction of thin-walled tubes using a die: Experimental and theoretical investigation. International Journal of Machine Tools and Manufacture, 46, 1643-1652.

4. Naveen Kumar Nayak et al., Optimization of Cnc Turning Parameters for Al-6061 Using Response Surface Methodology, International Journal of Mechanical and Production Engineering Research and Development (IJMPERD), Volume 7, Issue 4, July - August 2017, pp. 127-138

5. Alves ML, Almeida BPP, Rosa PAR, Martins PAF. (2006), End forming of thin-walled tubes. Journal of Material Processing Technology, 177, 183-187.

6. Alves LM, Martins PAF (2009). Cold expansion and reduction of thin-walled PVC tubes using a die. Journal of Materials Processing Technology, 209, 4229-4236.

7. Wang Lin, Chan LC, Lee TC(2007), Process modeling of controlled forming with time variant blank holder force using RSM method. International Journal of Machine Tools \& Manufacture, 47, 1929-1940.

8. Qi Zhanga, Kaiqiang Jina, Dong mua, Pengju Mab, Jie Tian(2014), Rotary swaging forming process of tube work pieces. 11th International Conference on Technology of Plasticity, 19-24 October.

9. Jay G Patel et al., To Study and Optimize the Process Parameter Throw Roller Burnishing Process on EN19 Material by Response Surface Methodology, International Journal of Mechanical and Production Engineering Research and Development (IJMPERD), Volume 6, Issue 6, November - December 2016, pp. 21-30

10. Farzan Barati(2015), A numerical approach for determination of flow curve and evaluation of frictional behavior of AZ61 magnesium alloy under elevated temperature forming conditions. Measurement, 74, 1-10. 
11. Jan Henriksen, Hakon O. Nordhagen, Hieu Nguyen Hoang, Michael R. Hansen, Fredrik Christopher Thrane(2015), Numerical and experimental verification of new method for connecting pipe to flange by cold forming. Journal of Materials Processing Technology, 220, 215-223.

12. Sieczkarek. P, Wernicke. S, Gies. S, Tekkaya. A. E, Krebs. E, Wiederkehr. P, Biermann. D, Tillmann. W, Stangier. D(2016), Wear behavior of tribologically optimized tool surfaces for incremental forming processes. Tribology International, 104, 6472.

13. Gabriel Centeno, Maria Beatriz Silva, Luis M. Alves, Carpóforo Vallellano, Paulo A. F. Martins (2016), towards the characterization of fracture in thin-walled tube forming. International Journal of Mechanical Sciences, 119, 12-22.

14. Borrego. M, Morales-Palma. D, Martínez-Donaire. A. J., Centeno. G., Vallellano. C (2016), Experimental study of holeflanging by single-stage incremental sheet forming. Journal of Materials Processing Technology, 237, 320-330.

15. Venugopal L, Davidson MJ, Selvaraj N (2013), Effect of elevated temperatures on the formability of AA 2014 thin walled tube ends. Materials and Manufacturing Processes, 28, 319-323. 